\title{
Cálculos das Constantes Espectroscópicas e do Tempo de Vida dos Complexos Formados por Metanol e Gases Nobres
}

Romário Sousa Silva ${ }^{1}(\mathrm{PG})^{*}$, Yuri Alves de Oliveira ${ }^{1}(\mathrm{PG})$, Henrique Vieira

Rivera Vila ${ }^{1}(\mathrm{PQ})$, Luiz Guilherme Machado de Macedo $^{2}(\mathrm{PQ})$, Ricardo Gargano ${ }^{1}(\mathrm{PQ})$. romariosousaunb@gmail.com

${ }^{1}$ Instituto de Física, Universidade de Brasília, Brasília - DF.

${ }^{2}$ Instituto de Ciências Biológicas, Universidade Federal do Pará, Belém, Brasil.

Palavras-chave: Metanol, Gases Nobres, Tempo de Vida, Constantes Espectroscópicas.

Diversos trabalhos encontrados na literatura têm avaliado a ligação das interações em complexos envolvendo gases nobres (com um tempo de vida longo) com muitas propriedades macroscópicas e microscópicas tais como a dependência da temperatura do coeficiente de difusão, viscosidade e parâmetros termodinâmicos de equilíbrio. Outros estudos importantes mostraram o desenvolvimento de técnicas experimentais onde a permeação dos gases inertes através de soluções de metanol e etanol é usada para determinar o coeficiente de difusividade próximo à temperatura de transição do vidro. O presente trabalho mostra um estudo dos cálculos das constantes espectroscópicas, energias rovibracionais e do tempo de vida dos complexos formados pelo metanol $\mathrm{CH}_{3} \mathrm{OH}$ e dos gases nobres $\mathrm{He}, \mathrm{Ne}, \mathrm{Xe}, \mathrm{Kr}$, $\mathrm{Ar}$ e Rn. Esses cálculos são desenvolvidos a partir das Curvas de Energias Potêncial (CEP's), obtidas pela forma analítica Improved Lennard-Jones (ILJ), utilizando parâmetros ajustáveis tais como energia de dissociação e distância de equilíbrio provenientes de dados experimentais e de estrutura eletrônica. As CEP's são utilizadas em dois métodos diferentes, o da Representação da Variável Discreta (DVR) e o método de Dunham. O DVR é a primeira metodologia para determinar as constantes espectroscópicas, onde é empregado os valores das energias rovibracionais obtidas via resolução da equação de Schrödinger da parte nuclear, e o método de Dunham é a segunda metodologia que faz uso da teoria da perturbação a fim de encontrar expressões para constantes espectroscópicas rovibracionais em função das derivadas das curvas de energias potenciais. O tempo de vida dos complexos é calculado por meio da teoria de Slater, que é uma formulação puramente dinâmica com a análise vibracional completa dos complexos. Entre os resultados encontrados, apresentamos na figura abaixo o tempo de vida determinados para os complexos aqui estudados. A partir desta figura verificamos que o tempo de vida do complexo $\mathrm{CH}_{3} \mathrm{OH}$ - He ficou abaixo de 1 ps para todo intervalo de temperatura considerado (200 - 500k). Esse resultado demonstra que esse complexo é considerado instável. Esse resultado esta de acordo com fato de não existir nenhum estado vibracional no poço da CEP do complexo metanol - hélio. Além disso, os tempos de vida para a menor (200k) e a maior (500k) temperatura considerada para o sistema $\mathrm{CH}_{3} \mathrm{OH}-\mathrm{Kr}$ concordam muito bem com os resultados disponíveis na literatura. 
Tempo de Vida dos Complexos $\mathrm{CH}_{3} \mathrm{OH}-\mathrm{Ng}(\mathrm{Ng}=\mathrm{Ar}, \mathrm{Kr}, \mathrm{Ne}, \mathrm{Xe}, \mathrm{He})$.

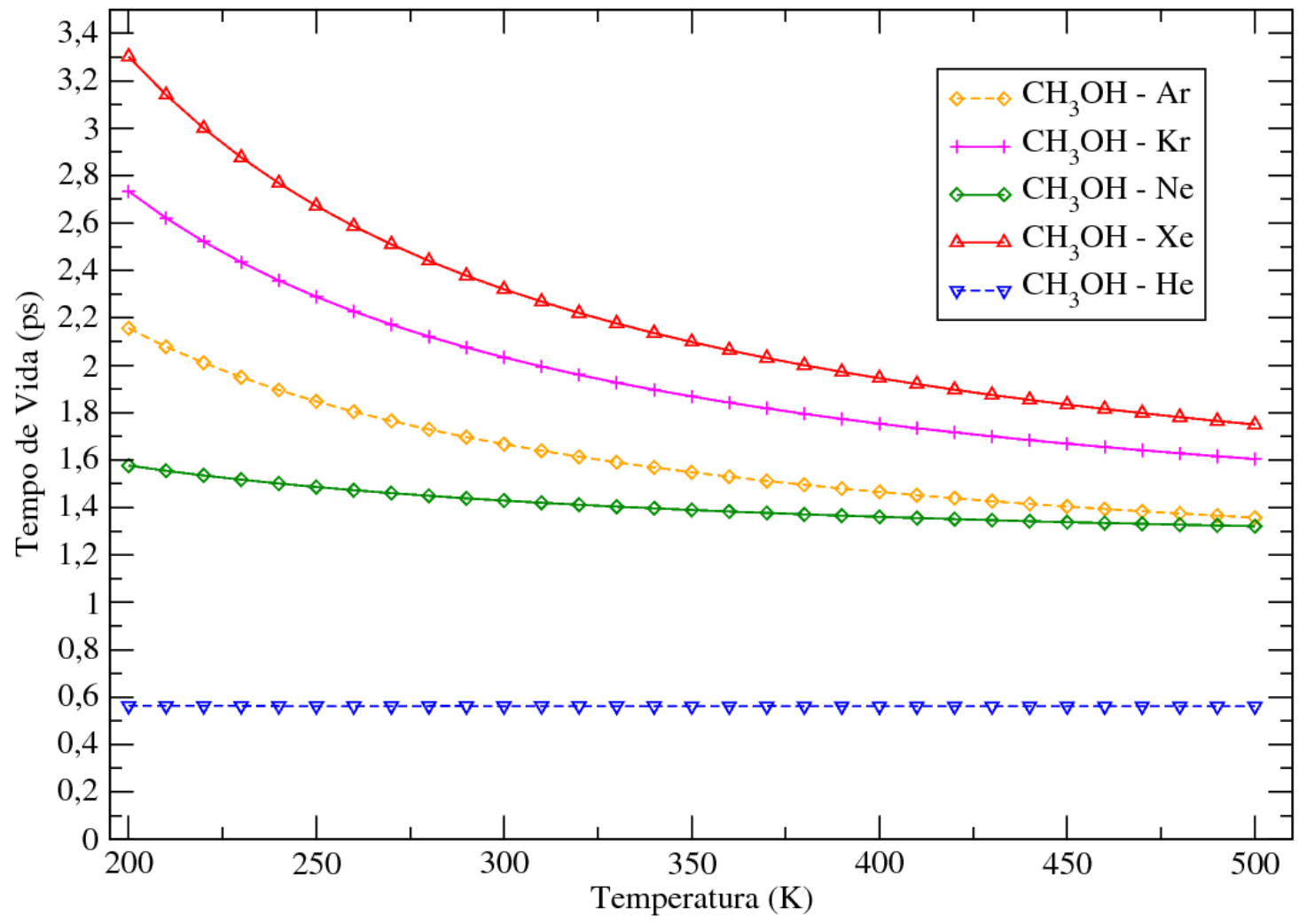

